\title{
Realidade da transparência passiva em prefeituras dos maiores municípios brasileiros
}

\author{
The reality of passive transparency in city halls of the major Brazilian municipalities \\ La realidad de la transparencia pasiva en las intendencias de los mayores municipios \\ brasileños
}

\section{Fabiano Maury Raupp}

Doutor em Administração na Universidade Federal da Bahia

Professor-Associado e Pesquisador do Departamento de Administração Empresarial e do Mestrado Acadêmico e Profissional em Administração do Centro de Ciências da Administração e Socioeconômicas, Universidade do Estado de Santa Catarina (ESAG/UDESC)

Endereço: Avenida Madre Benvenuta, 2037, Bairro Itacorubí

CEP: 88.035-001 - Florianópolis/SC - Brasil

E-mail: fabianoraupp@hotmail.com

Telefone: (48) 3664-8200

Artigo recebido em 19/05/2016. Revisado por pares em 05/08/2016. Reformulado em 10/08/2016. Recomendado para publicação em 30/08/2016 por Sandra Rolim Ensslin (Editora Científica). Publicado em 17/12/2016.

\section{Resumo}

O presente estudo teve por objetivo investigar a realidade da transparência passiva de prefeituras dos maiores municípios brasileiros. Foram considerados maiores municípios aqueles com população superior a 100.000 (cem mil) habitantes, totalizando 283 (duzentos e oitenta e três). Empreendeu-se um estudo descritivo, por meio de pesquisa survey, com abordagem qualitativa e quantitativa. Do total de prefeituras, 220 (duzentas e vinte) $(77,74 \%)$ foram consideradas (in)transparentes: em 11 (onze) (3,89\%) prefeituras os portais não permitiram o envio da solicitação, enquanto para 209 (duzentas e nove) $(73,85 \%)$ prefeituras este envio foi possível, porém não houve retorno satisfatório. Já 63 (sessenta e três) $(22,26 \%)$ prefeituras foram consideradas transparentes, pois o envio da solicitação ocorreu e o retorno foi considerado satisfatório. O descumprimento da lei ocorreu na maioria dos municípios, seja por problemas no portal, seja em razão de problemas no retorno às solicitações em que o envio foi possível.

Palavras-chave: Transparência passiva. Prefeituras. Maiores municípios brasileiros.

\section{Abstract}

The study aimed to investigate the passive transparency reality of the biggest Brazilian Municipality City Halls. It was considered the biggest municipalities those with a population greater than 100,000 inhabitants, totaling 283. It was a descriptive study through a survey with qualitative and quantitative approaches. The total amount of municipalities, 220 (77.74\%) were considered to have a lack of transparency: 11 (3.89\%) city halls the portals did not allow sending the request while for 209 (73.85\%) city halls was possible to send it but 
there was no satisfactory replies. On the other hand, 63 (22.26\%) city halls were considered transparent as the sending request happened and the replies were enough. The law violation occurred in most of the municipalities either by problems in the portal or due to problems in answering the requests where it was possible to send them.

Keywords: Passive transparency. City Halls. The Biggest Brazilian municipalities.

\section{Resumen}

El objetivo del estudio fue investigar la realidad de la transparencia pasiva de las intendencias de los mayores municipios brasileños. Se consideraron como mayores municipios a aquellos con una población superior a 100.000 habitantes, totalizando 283. Se inició un estudio descriptivo por medio de la investigación survey, con un abordaje cualitativo y cuantitativo. Del total de intendencias, 220 (77,74\%) fueron consideradas como no transparentes: en 11 (3,89\%) de ellas los portales no permitieron el envío de la solicitación, mientras que en 209 (73,85\%) de las mismas fue posible enviar la solicitación. Sin embargo, no hubo una respuesta satisfactoria. En cambio, 63 (22,26\%) intendencias fueron consideradas como transparentes, pues el envio de la solicitación y su correspondiente respuesta fueron considerados como satisfactorios. El incumplimiento de la ley se dio en la mayoría de los municipios, ya sea por problemas en el portal o en razón de problemas para responder las solicitaciones cuyos envíos fueron posibles.

Palabras claves: Transparencia pasiva. Intendencias. Mayores municipios Brasileños.

\section{Introdução}

A transparência tem tido destaque no debate do relacionamento do Estado com os seus jurisdicionados, e ocupa espaço na agenda nacional e internacional. Observa-se que o amadurecimento da democracia brasileira tem permitido a ampliação de mecanismos de controle social e do exercício da cidadania. O Estado brasileiro e, por consequência, a legislação pátria, acompanhando a tendência mundial, tem procurado tornar-se adequado às mudanças exigidas pela sociedade, ajustando o arcabouço legal nacional aos novos tempos (MACADAR; FREITAS; MOREIRA, 2015). Concomitantemente, percebe-se uma expansão da transparência pública para além da linha legal/fiscal, que passou a abordar outros aspectos da gestão pública (desempenho, pessoal, controles internos). Essa ampliação traz novos requisitos para a responsabilização pública, via órgãos de controle, que passam a avaliar se, efetivamente, as informações públicas estão acessíveis ao cidadão via portais eletrônicos, por exemplo (BAIRRAL; SILVA; ALVES, 2015).

$O$ exercício da transparência pode ser considerado uma forma de esclarecimento ao cidadão pelo Estado do que ocorre na sua esfera de competência, disponibilizando, com presteza, rapidez e correção, as informações que estão ao seu dispor. Significa, portanto, deixar o Estado aberto e visível ao cidadão (MACADAR; FREITAS; MOREIRA, 2015). Torna-se relevante ampliar o nível de transparência para que os cidadãos possam apreciar a prestação de contas e verificar se o desempenho está atendendo ao interesse coletivo (Silva, Pereira e Araújo, 2014). Esses fatores contribuem para que o debate sobre o tema seja de interesse tanto da opinião pública quanto dos meios acadêmicos (ZUCCOLOTTO; TEIXEIRA; RICCIO, 2015).

É o contexto apresentado acima que ancora o estudo aqui empreendido, orientado a 
partir da formulação da seguinte problemática: Qual a realidade da transparência passiva de prefeituras dos maiores municípios brasileiros? Para buscar respostas à problemática, o objetivo consistiu em investigar a transparência passiva de prefeituras dos maiores municípios brasileiros. Justifica-se o estudo no contexto acadêmico nacional, pois apesar de o tema suscitar interesse entre os pesquisadores, ainda pouco se sabe sobre o grau de divulgação das informações públicas e sobre os incentivos que afetam essa divulgação. Portanto, pesquisas científicas sobre o assunto se configuram numa oportunidade de contribuição para a realidade do setor público (BAIRRAL; SILVA; ALVES, 2015). Faz-se importante conhecer a gênese do fenômeno no país, acompanhar sua evolução, de forma a melhor compreender o atual estágio (MACADAR; FREITAS; MOREIRA, 2015). Particularmente em relação à transparência passiva, Raupp e Pinho (2015a) destacam uma lacuna na área de conhecimento, tendo em vista a quase ausência de trabalhos publicados em anais de eventos e em periódicos nacionais. Em termos práticos, os resultados poderão subsidiar um diagnóstico situacional da adequação ou não de prefeituras dos maiores municípios em relação à legislação, bem como da presença de outros indicadores, além da exigência legal, que ampliam o conceito de transparência passiva.

O artigo está estruturado em cinco seções, iniciando por esta introdução. A próxima seção discorre sobre os aspectos teóricos que sustentam o objeto de investigação: transparência, transparência passiva e o uso das tecnologias da informação e comunicação (TIC). A terceira seção contempla o percurso metodológico adotado. Os resultados apresentados na quarta seção desvendam a realidade da transparência passiva de prefeituras dos maiores municípios brasileiros. A quinta seção aborda as conclusões do estudo.

\section{Transparência, Transparência Passiva e o Uso das TIC}

A transparência dos atos dos gestores públicos é uma exigência legal e pode ser periodicamente acompanhada e fiscalizada pelo cidadão. Porém, uma gestão pública transparente vai além da divulgação dos instrumentos legais, e deve se estender à construção de condições de accountability, principalmente quando possibilita que os cidadãos acompanhem e participem efetivamente dos atos da administração pública (CRUZ et al., 2012). Mesmo considerando que o conceito de accountability ainda está em construção na realidade brasileira, Pinho e Sacramento (2009) constataram que o significado do conceito envolve: responsabilidade (objetiva e subjetiva), controle, transparência, obrigação de prestação de contas, justificativas para as ações que foram ou deixaram de ser empreendidas, premiação e/ou castigo.

Partindo do conceito de Pinho e Sacramento (2009), no presente estudo optou-se por considerar a transparência como uma das dimensões capazes de contribuir para a accountability.Para Filgueiras (2011), o conceito de transparência surge como um valor fundamental da gestão pública contemporânea; a sua realização significa ampliar as informações da sociedade acerca das ações realizadas pelos agentes públicos e, por esta via, fomentar a accountability. Zuccolotto, Teixeira e Riccio (2015) aduzem que o termo transparência tem sido tomado continuamente como sinônimo de solução para muitos problemas existentes numa ordem democrática.

A transparência é central para o exercício da accountability entre estados e cidadãos. Um governo transparente é aquele que promove abertura do sistema de governança através de 
processos e procedimentos claros e de fácil acesso à informação pública por parte dos cidadãos, estimulando a consciência ética no serviço público através do compartilhamento de informações. Esses fatores tendem a assegurar accountability para o desempenho dos indivíduos e organizações que são responsáveis por recursos públicos ou ocupam cargos públicos (SUK KIM et al., 2005). A transparência é geralmente definida como o princípio de permitir que o cidadão tenha a possibilidade de obter informações sobre as operações e estruturas de uma determinada organização pública. Da mesma forma, ela é muitas vezes considerada sinônimo de abertura e de divulgação (ETZIONI, 2010). No cerne da transparência está a comunicação efetiva dos resultados dos serviços gerados pelo poder público diretamente ao cidadão, mediante formas alternativas disponíveis à ampla gama de interessados (FRANCO et al., 2014). Neste sentido, cenários em que o histórico das opções políticas é desconhecido, e o eleitorado incapaz de punir os políticos que se envolvem em corrupção e outras formas de conduta ilegal, têm gerado preocupações que impulsionaram discussões em torno da transparência na gestão pública (FOX, 2007).

Os gestores públicos devem enfrentar e superar a opacidade que tradicionalmente reveste as ações administrativas, o que exigirá uma grande mudança de mentalidade em suas ações e um compromisso com a transparência.(CASADO, 2013)A transparência dissipa a opacidade, considerada um dos refúgios da corrupção, da ineficiência e da incompetência.(MICHENER, 2011) O objetivo da transparência é garantir a todos os cidadãos acesso às informações que explicitam as ações a serem praticadas pelos governantes, as em andamento e as executadas em períodos anteriores. Deve contemplar ampla divulgação, inclusive por meios eletrônicos e divulgação de audiências públicas, dos planos, diretrizes orçamentárias, orçamentos, relatórios periódicos da execução orçamentária e da gestão fiscal, além de pareceres prévios emitidos pelos tribunais de contas. A transparência não deve se reportar somente a fatos presentes, mas também ser garantida para informações de períodos anteriores, o que possibilita estudos de caráter evolutivo e comparativo acerca da atuação dos gestores. (SILVA, 2008)

Ainda que a transparência não deva se restringir às exigências legais, as discussões desta seção também consideram a perspectiva legal a fim de respaldar o objeto empírico. A transparência governamental constitui um dos elementos básicos da gestão fiscal responsável, indissociável da governança pública moderna. A transparência nas contas públicas passou a receber maior destaque na legislação brasileira em prol de uma gestão pública responsável e transparente. (ALLEGRETTI; PLATT NETO, 2010) Do ponto de vista legal, para Raupp e Pinho (2015b), a publicação da Lei n. ${ }^{\circ}$ 12.527, de 18 de novembro de 2011 (BRASIL, 2011), conhecida como Lei de Acesso à Informação - LAI, reforçou exigências legais de transparência dos atos praticados na administração pública. Algumas das exigências já constam no texto da Lei n. ${ }^{\circ} 101$, de 4 de maio de 2000 (BRASIL, 2000), conhecida como Lei de Responsabilidade Fiscal - LRF, bem como na Lei n. ${ }^{\circ}$ 131, de 27 de maio de 2009 (BRASIL, 2009), denominada comumente de Lei da Transparência.

Discorrendo um pouco sobre os textos legais, para Sacramento e Pinho (2007), a LRF integra o rol das medidas que contribuem para o avanço formal da transparência na administração pública brasileira. Entendem os autores que a sua efetivação depende diretamente do exercício da fiscalização de seu cumprimento pelos órgãos de controle aliados a uma ampla participação popular. A LRF estabelece regras obrigando os entes federativos a apresentarem demonstrativos fiscais que devem ser publicados em meios de amplo acesso público. A publicação destes demonstrativos na internet, por exemplo, tem como mérito 
intensificar o controle sobre as contas públicas dos municípios,principalmente pelas sanções fiscais aplicáveis no caso de seu descumprimento. Com isso, além dos tribunais de contas, do Ministério da Fazenda e do Ministério Público, os próprios cidadãos têm acesso à situação fiscal dos diversos governos. (LOUREIRO; TEIXEIRA; PRADO, 2008) Pelicioli (2000, p.110) define a LRF como "um sistema de planejamento, execução orçamentária e disciplina fiscal até então inexistente".

Conforme o art. 48 da LRF, são considerados instrumentos de transparência da gestão fiscal: "os planos, orçamentos e lei de diretrizes orçamentárias; as prestações de contas e o respectivo parecer prévio; o Relatório Resumido da Execução Orçamentária e o Relatório de Gestão Fiscal; e as versões simplificadas desses documentos (BRASIL, 2000)". Ainda no art. 48, em um parágrafo único incluído pela Lei da Transparência (BRASIL, 2009), consta que a transparência também será assegurada mediante:

I - Incentivo à participação popular e realização de audiências públicas, durante os processos de elaboração e discussão dos planos, lei de diretrizes orçamentárias e orçamentos;

II - Liberação ao pleno conhecimento e acompanhamento da sociedade, em tempo real, de informações pormenorizadas sobre a execução orçamentária e financeira, em meios eletrônicos de acesso público;

III - Adoção de sistema integrado de administração financeira e controle, que atenda a padrão mínimo de qualidade estabelecido pelo Poder Executivo da União e ao disposto no art. 48-A (BRASIL, 2009).

A Lei da Transparência também acrescentou à LRF que os entes da Federação disponibilizarão a qualquer pessoa física ou jurídica o acesso às informações referentes à despesa, como atos praticados pelas unidades gestoras no decorrer da execução da despesa, e à receita, como lançamento e recebimento de toda a receita das unidades gestoras, inclusive referente a recursos extraordinários. Novos avanços em termos legais foram introduzidos pela LAI, que legitima o novo paradigma pautado na transparência pública, e tem a publicidade como a regra geral e o sigilo como exceção, conferindo a qualquer cidadão a possibilidade de obter, junto à Administração Pública, informações que não estejam disponibilizadas em seus sítios eletrônicos, ressalvados os casos em que é resguardado o sigilo.(WARMLING; BERNARDES; SANTOS, 2014) De acordo com o art. 3 da LAI, os procedimentos previstos destinam-se a assegurar o direito fundamental de acesso à informação, em conformidade com os princípios básicos da administração pública e tendo como diretriz o desenvolvimento do controle social, fomentando o desenvolvimento da cultura da transparência. Estão previstas na lei duas tipologias de transparência: transparência ativa (dados disponibilizados espontaneamente que estejam ou não previstos na legislação pertinente); e transparência passiva (fornecimento de dados sob requerimento do interessado). As transparências ativa e passiva são frequentemente associadas às leis de acesso à informação. Contudo, a existência de uma lei de acesso à informação não faz um governo transparente. Para que um governo seja transparente, a informação deve ser acessível de forma completa e tempestiva.(MICHENER; BERSCH, 2013)

Em relação à transparência ativa, é dever dos órgãos e entidades públicas promover, independentemente de requerimentos, a divulgação em local de fácil acesso, no âmbito de suas competências, de informações de interesse coletivo geral por eles produzidas ou custodiadas. (BRASIL, 2011) A divulgação obrigatória em sítios oficiais da rede mundial de 
computadores (internet) deve ser objetiva, clara e em linguagem de fácil acesso. Os sítios ainda devem atender aos requisitos de garantia de autenticidade e integridade das informações disponíveis, mantê-las atualizadas, indicar o local e fornecer instruções que permitam ao interessado comunicar-se, por via eletrônica ou telefônica, com o órgão ou entidade detentora do sítio, além de adotar medidas necessárias para garantir a acessibilidade de conteúdo. Considerando o objeto empírico do presente estudo, discute-se um pouco mais acerca da transparência passiva.

Partindo do pressuposto de Silveira (2012) de que as informações públicas pertencem ao cidadão, e não ao Estado, as informações que não forem disponibilizadas de forma ativa pelos gestores públicos poderão ser solicitadas pelo cidadão, configurando a transparência passiva. A solicitação de informações pelo cidadão, contemplada no art. 10 da LAI, pode ocorrer presencialmente no serviço de informação do órgão ou através da internet. É solicitada a identificação do requerente que, no entanto, não necessita justificar as razões da sua solicitação. Se o acesso à informação não puder ocorrer de imediato, o órgão terá até 20 dias (contados de forma contínua, independentemente de passar por dias úteis ou não úteis) para responder, prorrogáveis por mais 10 dias (contados de forma contínua), mediante justificativa formal ao requerente. A LAI prevê possibilidades de recursos a serem interpostos pelo cidadão quando o acesso à informação for negado ou quando ele considerar que os processos previstos na LAI não foram respeitados pelo órgão público. (JARDIM, 2012). Para o atendimento do art. 10 da LAI, o ente governamental deverá considerar:

$\S 1^{\circ}$ Para o acesso às informações de interesse público, a identificação do requerente não pode conter exigências que inviabilizem a solicitação;

$\S 2^{\circ}$ Os órgãos e entidades do poder público devem viabilizar alternativa de encaminhamento de pedidos de acesso por meio de seus sítios oficiais na internet; e

$\S 3^{\circ}$ São vedadas quaisquer exigências relativas aos motivos determinantes da solicitação de informações de interesse público.

$\mathrm{Na}$ transparência passiva, embora as informações sobre o desempenho governamental sejam,de forma geral, públicas, são necessárias algumas ações para obtê-las, como um pedido de informações, por exemplo.(BRANS; PETERS; VERBELEN, 2012) O pedido não necessita de fundamentação, motivação ou demonstração de interesse.(SILVEIRA, 2012) Portanto, a transparência passiva é um dos fortes eixos de promoção do controle social, pois, com um formulário bastante simples, possibilita que o cidadão formalize seu pedido de informação de forma fácil e rápida.(LOPES; ASSUMPÇÃO, 2013)Contudo, a descrição da informação requerida deve ser clara, objetiva e precisa a ponto de identificar o objeto do pedido e possibilitar, de forma eficiente e eficaz, a busca da informação pelo Estado.(SILVEIRA, 2012) Os órgãos públicos têm a responsabilidade de atender às demandas de transparência passiva dos cidadãos e, nesse sentido, estas atividades devem, em alguma medida, ser incorporadas às rotinas administrativas dos servidores. Caso contrário, há o risco de se anular o direito de acesso à informação trazido pela LAI. (MICHENER; MONCAU; VELASCO, 2014)Os governos devem, portanto, mudar suas atitudes, muitas vezes relutantes em fornecer informações aos requerentes, mesmo não existindo base legal para que isso ocorra. Para que haja mudanças neste sentido, é essencial um compromisso com a transparência, a fím de que o direito de acesso à informação seja exercido de forma real e eficaz.(CASADO, 2013)

Embora o cidadão seja um personagem central no cenário da LAI, o papel da sociedade 
é exclusivamente o da transparência passiva. Todos os demais mecanismos acionados e acionáveis para a implementação da LAI são basicamente aparatos do Estado. Se as agências que configuram o aparato informacional do Estado, especialmente os arquivos, não construírem agendas, políticas e práticas em diálogo com a LAI, provavelmente seguirão periféricas. (JARDIM, 2012) Para Raupp e Pinho (2015a), a transparência passiva pode ser vista como aquela encontrada em uma sociedade mais desenvolvida, mais participativa, o que não é o caso da sociedade brasileira. A reflexão acerca do acesso à informação no Brasil permeia questões culturais, econômicas, políticas e sociais, já que se trata de questões que constroem uma sociedade. (NIWA; LIMA, 2013)

Em um estudo realizado pelo Artigo 19 sobre o acesso à informação no Brasil, foram submetidos mais de 140 (cento e quarenta) pedidos de informação para diferentes órgãos da administração pública federal, estadual e municipal com relação às seguintes áreas temáticas: meio ambiente, educação, moradia, saúde, direito da mulher, acesso à água, radiodifusão, pluralismo e diversidade, e implementação da lei de acesso à informação. Os resultados deste esforço indicam que menos da metade das respostas recebidas contemplaram integralmente o que foi perguntado. Outro resultado preocupante é que o número de pedidos não respondidos ainda é extremamente alto: $32 \%$ dos órgãos requisitados não responderam, mesmo após 20 (vinte) dias (contados de forma contínua) decorridos do prazo estabelecido pela LAI.(ARTIGO 19, 2013) A transparência passiva, por sua vez, teve avanços significativos, mas ainda requer grandes esforços das autoridades públicas, dos servidores e da sociedade civil para garantir o acesso à informação a todos os indivíduos de forma igualitária. Segundo oArtigo 19 (2013), os pontos mais problemáticos são: a necessidade de identificação do requerente representa um entrave para o acesso igualitário às informações, principalmente em pequenos municípios em que a lógica do poder ainda predomina; o grau de insatisfação com as respostas é alto, pois os órgãos públicos, em geral, não respondem ao que foi perguntado; a divulgação dos dados orçamentários e executivos, obrigação estabelecida por leis anteriores à LAI, ainda é falha e impede o real acesso à informação; a publicação da lista de documentos classificados como sigilosos e suas respectivas justificativas, como requer a LAI, também parece ser um ponto descumprido de forma generalizada pelos órgãos públicos; a elaboração e o envio dos recursos ao pedido de informação não é um procedimento simples e requer conhecimento prévio sobre as autoridades competentes para julgá-lo, o controle de prazos etc.

No estudo realizado por Michener, Moncau e Velasco (2014), foram enviados 453 (quatrocentos e cinquenta e três) pedidos de acesso à informação baseados em 55 (cinquenta $\mathrm{e}$ cinco) perguntas individuais. Essas perguntas foram destinadas a 133 (cento e trinta e três) órgãos públicos pertencentes a todos os poderes dos estados de São Paulo, Minas Gerais e Rio de Janeiro, bem como suas respectivas capitais, além do Distrito Federal e da União. Para avaliação do Poder Judiciário foram enviados 264 (duzentos e sessenta e quatro) pedidos de acesso à informação baseados em 7 (sete) perguntas individuais. Os pedidos foram enviados a 40 (quarenta) tribunais: os 27 (vinte e sete) Tribunais de Justiça Estaduais, os 5 (cinco) Tribunais Regionais Federais e os 5 (cinco) Tribunais Regionais do Trabalho, além do Supremo Tribunal Federal, Superior Tribunal de Justiça e Tribunal Superior do Trabalho. As taxas de resposta foram de $69 \%$ na avaliação geral e $61 \%$ na avaliação do Poder Judiciário. Cabe destacar, porém, que algumas entidades apresentaram resultados muito distantes das médias. É o caso dos governos do Estado do Rio de Janeiro e do Município do Rio de Janeiro na Avaliação Geral, que apresentaram taxas de resposta de $34 \%$ e $23 \%$, evidenciando um cenário preocupante em termos de cumprimento com a LAI. Com relação à Avaliação do 
Poder Judiciário, alguns Tribunais de Justiça também apresentaram taxas de resposta consideravelmente baixas, como, por exemplo, o TJ-AC e o TJ-AL. (MICHENER. MONCAU. VELASCO, 2014)

$\mathrm{Na}$ pesquisa realizada com o objetivo de investigar o atendimento às exigências de transparência passiva pelas câmaras de municípios brasileiros com população superior a 300.000 (trezentos mil) habitantes, Raupp e Pinho (2015a) constataram que a maioria das câmaras $(84,81 \%)$ descumpriram as exigências legais e mostraram-se intransparentes na forma passiva. Foram poucas as câmaras $(15,19 \%)$ que retornaram de forma satisfatória o requerimento enviado. Destacam os autores que a defasagem entre as exigências de transparência impostas aos entes governamentais e o efetivo cumprimento por seus dirigentes não é prerrogativa da transparência ativa, mas ocorre também com a transparência passiva. Portanto, não é possível afirmar que a transparência passiva seja um caminho para amenizar o descumprimento dos governantes em relação à transparência dos atos praticados na gestão pública. Os dados obtidos com essa pesquisa mostram-se ainda mais preocupantes ao se considerar que foram investigadas as câmaras das cidades maiores -que se esperava fossem mais desenvolvidas - do contexto nacional. (RAUPP; PINHO, 2015a)

Ao mesmo tempo, compartilhando um pensamento mais otimista, percebe-se que pode estar em marcha um processo de atendimento à lei e à cidadania através da transparência passiva, o que deve ser visto como alvissareiro na trajetória histórica brasileira.(RAUPP; PINHO, 2015a) São muitos os benefícios que se pretende alcançar com a adoção de mecanismos de transparência a partir de uma lei geral de acesso à informação: combate à corrupção; enfrentamento de abusos por parte de agentes governamentais não comprometidos com a democracia e o bem comum; defesa dos direitos humanos; eficiência na gestão pública; melhoria do debate público e reforço na participação cidadã.(ANGÉLICO; TEIXEIRA, 2012) Por outro lado, também podem ser apontados obstáculos socioculturais que dificultam o fortalecimento da LAI. São eles: falta de divulgação a respeito do direito à informação; falta de apoio à Lei por parte de setores que já têm acesso às informações; ausência do uso prático das possibilidades da Lei, com receio de retaliação governamental; fraca atuação da sociedade, tanto no sentido de demandar informação como no sentido de demandar reformas institucionais para fortalecer o direito à informação.(ANGÉLICO, 2012) Pontualmente em relação ao aparato institucional-legal, o autor destaca os seguintes obstáculos: ausência de órgão supervisor ou baixa autonomia dos órgãos existentes; limitado escopo da Lei; ausência de referência legal em relação ao fato de que a não resposta é violação ao direito à informação. Trata-se de obstáculos que dificultam a efetiva construção de condições de transparência no setor público. (BRANS; PETERS; VERBELEN, 2012)

A criação de uma legislação é apenas uma etapa na construção de uma política de transparência no País. A norma deve ser transformada em ações e fatos, pelo Executivo e demais poderes, para sua efetivação, possibilitando maior conhecimento da população sobre os atos do governo, tentando eliminar a desconfiança sem que se perca o interesse. (PAES, 2011) Aliado a isso, os prestadores de serviços públicos vêm sendo desafiados no sentido de promover inovações tecnológicas que transformem, ou ajudem a transformar, a relação entre o Estado e o cidadão. A premissa de facilitar e simplificar o acesso à informação pelo cidadão, como é o caso da transparência ativa e passiva, pode ser considerada uma inovação. A solução foi concebida de forma a livrar o cidadão do labirinto de formulários e da burocracia do serviço público. (LOPES; ASSUMPÇÃO, 2013)

A compreensão da evolução da transparência como norma, em termos de divulgação 
voluntária de informações por atores políticos, envolve questões de poder e persuasão em um contexto inerentemente político. Embora nem sempre a transparência, no sentido da divulgação voluntária de informaçõespor atores públicos, esteja relacionada à legitimidade, argumenta-se que ela pode contribuir para uma aceitação pública das estruturas institucionais. De acordo com a teoria política, elapode propiciar aos cidadãos a possibilidade de acompanhar a formulação de políticas e examinar seus resultados, reforçando a legitimidade das estruturas institucionais. Entende-se que a internet desempenha um importante papel na construção da transparência dos governos e, portanto, reforça a sua legitimidade. (CURTIN; MEIJER, 2006; LICHT, 2014) Para Lopes (2007), foi a partir de meados da década de 1990 devido ao grande impulso com a virada do século - que os investimentos em políticas de acesso à informação pública, nos países onde esse acesso já estava mais bem estruturado, passaram a ser canalizados principalmente para as TIC, com destaque para a internet. Segundo o mesmo autor, a revolução trazida pelas TIC tem causado profundas mudanças na organização do setor público. Este fato pode ser comprovado com exemplos práticos de como a tecnologia tem ajudado de diversas formas a facilitar a promoção de serviços públicos em maior quantidade e qualidade. A discussão sobre a disponibilização de informações pelos entes públicos à sociedade tem sido relacionada ao uso das TIC, com promessas de facilidades no acesso à informação a partir dessas tecnologias. (RAUPP; ABREU; ABREU, 2015)

A internet, por suas características, permite que grande quantidade de informações esteja acessível a um maior número de pessoas, servindo de ferramenta para a transparência.(ALLEGRETTI; PLATT NETO, 2010) Uma das principais contribuições que o uso da internet pode trazer para a divulgação das ações governamentais é a redução do custo do exercício da cidadania, uma vez que o cidadão terá a oportunidade de despender uma quantidade menor de tempo e dinheiro para a obtenção das informações do seu interesse, consolidando os fundamentos de uma sociedade democrática e plural.(SANTANA JUNIOR et al., 2009)

Para Oliveira (2006), a Administração Pública deveria buscar a introdução das TIC às suas funções, organizando-as em termos de coletar e prover dados, consequentemente gerando informações claras, precisas e concisas na tentativa de tornar os serviços essencialmente públicos acessíveis a todos. Com isso, percebe-se a importância crescente que as TIC representam no setor público, podendo tornar-se aliadas no processo de transparência, facilitando o acesso à informação. É evidente que a popularização da internet nas duas últimas décadas promoveu uma revolução nos meios de informação. A rapidez, a facilidade de acesso e a disponibilidade de informações deram início a uma verdadeira Era da Informação. Ao mesmo tempo, têm sido desenvolvidos sistemas de informações cada vez mais complexos, agregando banco de dados, informações espaciais, interligando processos, transações econômicas e serviços. Esses avanços têm atingido também os governos. (PRADO; LOUREIRO, 2006)

Sistemas de informação têm sido implantados por governos e são configurados como portais eletrônicos, permitindo o acesso a uma grande quantidade de serviços on-line, dados e informações de interesse público. (PRADO; LOUREIRO, 2006) Oportuno definir o conceito de portal eletrônico que, para Cunha (2000, p.1), "ser reconhecido como um portal está diretamente relacionado à força com que o site atrai visitantes. Os serviços mais comuns de um portal incluem serviços de e-mail, bate-papo (chat), serviços de busca e serviços de notícias, gratuitos ou não". Parte-se do entendimento de que, dependendo dos objetivos e da forma com que são implementados, os portais eletrônicos podem contribuir para a construção 
da transparência. Por outro lado, corre-se o risco, quando da criação de um portal eletrônico, de que o mesmo sirva apenas de mural eletrônico e que não haja transparência. (RAUPP, 2011) No caso particular do presente estudo, a investigação da transparência passiva assentouse no envio de solicitação de informação pelo próprio portal ou a partir de orientações apresentadas no portal (por exemplo, disponibilização de endereço de e-mail), conforme abordado na trajetória metodológica.

\section{Trajetória Metodológica}

Para realizar a pesquisa, empreendeu-se um estudo descritivo, realizado por meio de um survey, com abordagem qualitativa e quantitativa. Foram investigadas as prefeituras dos maiores municípios brasileiros, assim considerados aqueles com população superior a 100.000 (cem mil) habitantes. Para identificar os maiores municípios, foi consultada a Sinopse do Censo Demográfico 2010, do Instituto Brasileiro de Geografia e Estatística (IBGE), a partir da qual chegou-se a 283 (duzentos e oitenta e três) municípios. Algumas razões para trabalhar com os maiores municípios são apresentadas abaixo:

- Municípios maiores tendem a apresentar maior nível de divulgação de informações acerca da gestão municipal (STYLES; TENNYSON, 2007);

- Assume-se que deve haver, nos municípios maiores, com a existência de uma sociedade mais complexa e plural, a busca de maior cobrança aos poderes instituídos, entre eles o Executivo municipal, por parte da sociedade civil (RAUPP; PINHO, 2011);

- O conjunto de municípios com mais de 100.000 (cem mil) habitantes concentra milhões de habitantes, o que torna o estudo relevante, uma vez que investiga informações relativas à gestão pública para uma parcela bastante significativa da população brasileira (CRUZ et al., 2012);

- Municípios maiores devem ter suas prefeituras com maiores condições (financeiras, de recursos humanos) de construir portais mais desenvolvidos, contemplando inclusive o quesito da accountability. (RAUPP, 2014)

Após a identificação dos municípios com mais de 100.000 (cem mil) habitantes, seguiu-se com a verificação dos endereços dos portais eletrônicos das prefeituras. A busca dos endereços foi feita no site Google, nos dias 2 e 3 de setembro de 2015. Os endereços foram identificados a fim de que a solicitação da informação ocorresse a partir do formulário eletrônico disponível no próprio portal ou por meio de e-mail, cujo endereço também seria obtido no portal. Para a coleta dos dados, formulou-se um requerimento único para ser encaminhado às prefeituras, com o seguinte texto: "Considerando os pressupostos da Lei ${ }^{\circ}{ }^{\circ} 12.527 / 2011$, solicito lista de viagens internacionais realizadas pelo prefeito em 2014, com detalhes do objetivo e o valor do gasto total com diárias por viagem". O envio da solicitação ocorreu nos dias 14,15 e 16 de setembro de 2015. Ressalva-se que não foi fixado um prazo para retorno das informações, pressupondo que seria de conhecimento das prefeituras os limites legais definidos pela LAI.

Os dados obtidos foram analisados a partir da técnica da análise descritiva, tabulados em planilhas eletrônicas. Na apresentação dos resultados, optou-se por utilizar as categorias de Raupp e Pinho (2015a) que, adaptadas ao objeto investigado, restaram assim: primeira categoria - refere-se às prefeituras em que não foi possível encaminhar a solicitação de 
informação; segunda categoria - prefeituras cuja solicitação foi encaminhada, mas não houve retorno (resposta), ou o retorno foi insuficiente, ou o retorno ocorreu após o prazo legal; terceira categoria - prefeituras em que a solicitação foi encaminhada e houve retorno satisfatório.

\section{Realidade da Transparência Passiva}

A seção de resultados exibe, primeiramente, os resultados individuais obtidos em cada categoria. Em seguida, é apresentada uma síntese da (in)transparência passiva de prefeituras dos maiores municípios brasileiros.

\subsection{Prefeituras com portais que não permitiram o envio da solicitação}

Transcorridos aproximadamente 4 (quatro) anos da LAI, ainda há prefeituras cujo portal não está devidamente estruturado para receber a solicitação do cidadão. Nesta categoria identificou-se 11(onze) (3,89\%) prefeituras em que foram esgotadas as possibilidades de envio do pedido de informação (formulário eletrônico ou identificação de e-mail para envio da solicitação) por meio do portal eletrônico. No estudo de Raupp e Pinho (2015a), para $13,92 \%$ das câmaras investigadas não foi possível encaminhar o pedido de informação. Além de representar um percentual superior aos resultados obtidos com prefeituras, surpreendeu o fato de que este grupo contempla câmaras de 5 (cinco) capitais brasileiras e outras localizadas em cidades de grande porte e em regiões mais desenvolvidas. Em outras palavras, nesses centros seria esperado não encontrar problemas de limitações de artefatos tecnológicos nas câmaras municipais. Para Michener, Moncau e Velasco (2014), muitas entidades adotam plataformas ou sistemas que impõem obstáculos ao cidadão. Além disso, existem órgãos públicos brasileiros que sequer possuem plataforma específica para o recebimento de pedidos de acesso à informação.

A existência de prefeituras nesta categoria remete a algumas considerações. Primeiramente, há um claro desrespeito à lei. É o chamado descumprimento na origem (RAUPP; PINHO, 2015a), pois, de acordo com a LAI, art. 10, § $1^{\circ}$, "os órgãos e entidades do poder público devem viabilizar alternativas de encaminhamento de pedidos de acesso por meio de seus sítios oficiais na internet". (BRASIL, 2011) Outra consideração diz respeito ao fato de que essas prefeituras não contribuem para a construção de condições de transparência da administração municipal. Para Raupp e Pinho (2015a), se não há condições tecnológicas, sítios devidamente estruturados, o cidadão não consegue fazer o requerimento da informação. Neste conjunto de prefeituras, o administrador municipal desconhece a necessidade de informação do cidadão.

Os municípios de Campinas (SP), Caxias (MA), Codó (MA), Criciúma (SC), Maracanaú (CE), Maranguape (CE), Rio Grande (RS), São Bernardo (SP), Sete Lagoas (MG), Teresópolis (RJ) e Várzea Grande (MT), enquadrados na primeira categoria de Raupp e Pinho (2015a), parecem não fazer parte da realidade apresentada por Macadar, Freitas e Moreira (2015), para quem, na medida em que a tecnologia facilita o compartilhamento da informação, cabe ao Estado fornecer os elementos que permitam ao cidadão construir o seu livre convencimento dentro do universo do qual é titular, para, munido desses insumos, influir, pressionar, decidir, exigir providências, enfim, participar ativamente nos rumos do seu município, estado e país. Os portais verificados assumem mais um perfil de murais eletrônicos do que espaços de construção da transparência. Eles respondem a um requerimento, um 
impulso da modernidade expresso por um imperativo tecnológico dominante, porém não contribuem para o desenvolvimento da transparência. (RAUPP; PINHO, 2013) A princípio, era de se pressupor que estes municípios, por fazerem parte dos maiores municípios brasileiros, não teriam dificuldades para disponibilizar portais mais estruturados do ponto de vista tecnológico, ou seja, aptos a receber e, consequentemente, responder à solicitação do cidadão. Contudo, tais potencialidades do executivo não foram observadas nesta categoria. Também não foi observada a facilidade de acesso à informação pelos mecanismos da transparência passiva, pois, de acordo com Lopes e Assumpção (2013), a solicitação deveria ocorrer a partir de um formulário simples, que possibilitasse a formalização do pedido de forma fácil e rápida. Tais questões chamam atenção de forma negativa, dado o porte populacional dos municípios investigados.

\subsection{Prefeituras que não atenderam à solicitação}

E quando a tecnologia existe, mas não é utilizada para o fim a que se propõe? Essa é a realidade de um expressivo número de municípios: Cabo Frio (RJ), Abaetetuba (PA), Açailândia (MA), Águas Lindas de Goiás (GO), Alagoinhas (BA), Almirante Tamandaré (PR), Alvorada (RS), Americana (SP), Ananindeua (PA), Anápolis (GO), Angra dos Reis (RJ), Aparecida de Goiânia (GO), Aracaju (SE), Araçatuba (SP), Araguaína (TO), Araguari $(\mathrm{MG})$, Arapiraca (AL), Arapongas (PR), Araraquara (SP), Araras (SP), Araucária (PR), Bacabal (MA), Bagé (RS), Balneário Camboriú (SC), Barbacena (MG), Barreiras (BA), Barretos (SP), Bauru (SP), Belém (PA), Belford Roxo (RJ), Belo Horizonte (MG), Bento Gonçalves (RS), Boa Vista (RR), Botucatu (SP), Bragança (PA), Brusque (SC), Cabo de Santo Agostinho (PE), Cachoeiro de Itapemirim (ES), Camaçari (BA), Camaragibe (PE), Cametá (PA), Campina Grande (PA), Campo Largo (PR), Campos dos Goytacazes (RJ), Canoas (RS), Carapicuíba (SP), Cariacica (ES), Castanhal (PA), Catanduva (SP), Caucaia (CE), Colatina (ES), Conselheiro Lafaiete (MG), Coronel Fabriciano (MG), Cotia (SP), Crato (CE), Cubatão (SP), Cuiabá (MT), Diadema (SP), Divinópolis (MG), Dourados (MS), Duque de Caxias (RJ), Embu (SP), Eunápolis (BA), Feira de Santana (BA), Ferraz de Vasconcelos (SP), Florianópolis (SC), Formosa (GO), Fortaleza (CE), Foz do Iguaçu (PR), Francisco Morato (SP), Franco da Rocha (SP), Garanhuns (PE), Goiânia (GO), Governador Valadares (MG), Gravataí (RS), Guarapari (ES), Guarapuava (PR), Guarulhos (SP), Ibirité (MG), Igarassu (PE), Ilhéus (BA), Imperatriz (MA), Indaiatuba (SP), Ipatinga (MG), Itabira (MG), Itaboraí (RJ), Itaguaí (RJ), Itajaí (SC), Itapevi (SP), Itapipoca (CE), Itaquaquecetuba (SP), Itu (SP), Jaboatão dos Guararapes (PE), Jacareí (SP), Jandira (SP), Jaú (SP), Jequié (BA), Joinville (SC), Juazeiro (BA), Juazeiro do Norte (CE), Jundiaí (SP), Lages (SC), Lauro de Freitas (BA), Linhares (ES), Luziânia (GO), Macaé (RJ), Maceió (AL), Magé (RJ), Manaus (AM), Marabá (PA), Maricá (RJ), Maringá (PR), Marituba (PA), Mauá (SP), Mogi das Cruzes (SP), Montes Claros (MG), Mossoró (RN), Muriaé (MG), Natal (RN), Nilópolis (RJ), Niterói (RJ), Nossa Senhora do Socorro (SE), Nova Friburgo (RJ), Nova Iguaçu (RJ), Olinda (PE), Osasco (SP), Ourinhos (SP), Paço do Lumiar (MA), Palmas (TO), Paranaguá (PR), Parauapebas (PA), Parintins (AM), Parnaíba (PI), Passos (MG), Patos (PB), Patos de Minas (MG), Paulista (PE), Paulo Afonso (BA), Pelotas (RS), Petrolina (PE), Petrópolis (RJ), Piracicaba (SP), Poá (SP), Ponta Grossa (PR), Porto Alegre (RS), Porto Seguro (BA), Porto Velho (RO), Pouso Alegre (MG), Praia Grande (SP), Presidente Prudente (SP), Queimados (RJ), Resende (RJ), Ribeirão das Neves (MG), Ribeirão Preto (SP), Rio das Ostras (RJ), Rio Verde (GO), Rondonópolis (MT), Sabará (MG), Salto (SP), Salvador (BA), Santa Bárbara 
d'Oeste (SP), Santa Cruz do Sul (RS), Santa Luzia (MG), Santa Maria (RS), Santa Rita (PB), Santana de Parnaíba (SP), Santana (AP), Santarém (PA), Santos (SP), São Caetano do Sul (SP), São Carlos (SP), São Gonçalo (RJ), São João de Meriti (RJ), São José de Ribamar (MA), São José dos Campos (SP), São José dos Pinhais (PR), São Leopoldo (RS), São Lourenço da Mata (PE), São Luís (MA), São Mateus (ES), São Vicente (SP), Sapucaia do Sul (RS), Serra (ES), Simões Filho (BA), Sinop (MT), Sobral (CE), Sumaré (SP), Suzano (SP), Taboão da Serra (SP), Tatuí (SP), Taubaté (SP), Teixeira de Freitas (BA), Teófilo Otoni (MG), Timon (MA), Três Lagoas (MS), Trindade (GO), Uberlândia (MG), Umuarama (PR), Uruguaiana (RS), Valinhos (SP), Valparaíso de Goiás (GO), Varginha (MG), Várzea Paulista (SP), Vespasiano (MG), Viamão (RS), Vitória (ES), Vitória de Santo Antão (PE), Volta Redonda (RJ), Votorantim (SP).

Foram 209 (duzentas e nove) (73,85\%) prefeituras classificadas na segunda categoria, ou seja, para as prefeituras destes municípios a solicitação foi encaminhada, mas não houve retorno, ou o retorno ocorreu no prazo legal e foi considerado insuficiente, ou o retorno ocorreu após o prazo legal e também foi considerado insuficiente. Resultados semelhantes foram obtidos no estudo de Raupp e Pinho (2015a), considerando que 86,08\% das câmaras municipais puderam ser enquadradas nesta categoria. Por outro lado, as taxas de não atendimento às solicitações apontadas nos estudos do Artigo 19 (2013) e de Michener, Moncau e Velasco (2014) são bem inferiores, respectivamente 32\% e 31\%. Os resultados obtidos com prefeituras e aqueles obtidos com câmaras por Raupp e Pinho (2015a) parecem coadunar com Pinho (2008), quando explica que o problema não é de tecnologia, mas de cultura política, de desenvolvimento político. Destaca o autor que há muita tecnologia, ainda que ela possa e deva ser ampliada, mas pouca democracia, pois a tecnologia que poderia ser usada para o aperfeiçoamento democrático não é mobilizada nesse sentido. Nestes casos, o governo municipal ainda não teria condições de incorporar a cultura de utilização das TIC.

Ainda que algumas prefeituras desta categoria tenham feito contato (dentro e fora do prazo legal), estas não atenderam ao pedido de solicitação. Dissecando os resultados, 167 (cento e sessenta e sete) (59,01\%) prefeituras não deram retorno; 27 (vinte e sete) $(9,54 \%)$ prefeituras entraram em contato no prazo, contudo, o retorno foi considerado insuficiente; e 15 (quinze) (5,30\%) prefeituras entraram em contato após o prazo legal, cujo retorno também foi considerado insuficiente. Para que atendessem de forma satisfatória, as prefeituras deveriam informar a lista de viagens internacionais realizadas, os objetivos de cada viagem e o gasto com diárias em cada uma das viagens. Atentando para o fato de que os motivos de insuficiência foram comuns para os retornos recebidos dentro e fora do prazo, constatados a partir da análise do conteúdo, fez-se uma análise conjunta dos motivos para as 42 (quarenta e duas) prefeituras, chegando-se aos seguintes resultados: 17 (dezessete) (6,01\%) prefeituras informaram apenas a lista de viagens; 14 (catorze) (4,95\%) informaram a lista de viagens e os respectivos objetivos; 9 (nove) $(3,18 \%)$ prefeituras informaram a lista de viagens e os respectivos valores de diárias; e 2 (duas) $(0,71 \%)$ prefeituras entraram em contato informando que futuramente responderiam à solicitação, o que não ocorreu.

Algumas das características identificadas nesta categoria já haviam sido pontuadas pelo Artigo 19, em um monitoramento do acesso à informação: sistemas eletrônicos para envio de pedidos de informação que apresentam limite de caracteres ou de perguntas; órgãos que apresentam requisitos complexos, exigindo que o requerente saiba para qual seção interna do órgão o pedido deve ser dirigido; e requisitos de identificação que geram constrangimentos. (ARTIGO 19, 2013) Também foi possível constatar características semelhantes aos achados 
do estudo de Raupp e Pinho (2015a), a saber: determinadas prefeituras entraram em contato após o envio da solicitação, informando que iriam providenciar a resposta, contudo, não a encaminharam dentro do prazo limite definido pela LAI; outras solicitaram que o pedido fosse feito de forma presencial, in loco, na sede da prefeitura; além dos já mencionados requisitos de identificação com documentos pessoais para que a informação pudesse ser disponibilizada. Para os autores, trata-se de possíveis barreiras ao acesso à informação. Estas prefeituras, assim como as prefeituras da primeira categoria, também descumpriram a legislação e, em uma perspectiva de valor fundamental, não contribuíram para a construção do exercício da transparência.

\subsection{Prefeituras que atenderam à solicitação: uma inversão entre a regra e a exceção}

Fizeram parte da última categoria as prefeituras em que a solicitação foi encaminhada e houve retorno satisfatório. Foram identificadas 63 (sessenta e três) $(22,26 \%)$ prefeituras classificadas nesta categoria, correspondendo aos seguintes municípios: Apucarana (PR), Araruama (RJ), Atibaia (SP), Barra Mansa (RJ), Barueri (SP), Birigui (SP), Blumenau (SC), Bragança Paulista (SP), Brasília (DF), Cachoeirinha (RS), Campo Grande (MS), Caraguatatuba (SP), Caruaru (PE), Cascavel (PR), Caxias do Sul (RS), Chapecó (SC), Colombo (PR), Contagem (MG), Corumbá (MS), Curitiba (PR), Franca (SP), Guaratinguetá (SP), Guarujá (SP), Hortolândia (SP), Itabuna (BA), Itapecerica da Serra (SP), Itapetininga (SP), Itatiba (SP), Jaraguá do Sul (SC), Ji-Paraná (RO), João Pessoa (PB), Juiz de Fora (MG), Limeira (SP), Londrina (PR), Macapá (AP), Marília (SP), Mesquita (RJ), Mogi Guaçu (SP), Novo Hamburgo (RS), Palhoça (SC), Parnamirim (RN), Passo Fundo (RS), Pindamonhangaba (SP), Pinhais (PR), Poços de Caldas (MG), Recife (PE), Ribeirão Pires (SP), Rio Branco (AC), Rio Claro (SP), Rio de Janeiro (RJ), Santo André (SP), São José (SC), São José do Rio Preto (SP), São Paulo (SP), Sertãozinho (SP), Sorocaba (SP), Teresina (PI), Toledo (PR), Ubá (MG), Uberaba (MG), Vila Velha (ES), Vitória da Conquista (BA). Resultados aproximados foram obtidos por Raupp e Pinho (2015a), porém, distantes dos resultados obtidos pelo Artigo 19 (2013) e por Michener, Moncau e Velasco (2014).

Recorrendo àquilo que pretende expressar o título desta seção, nesta categoria parece ocorrer uma inversão entre a regra e a exceção. Isto decorre do fato de que a minoria é que atende à legislação, quando deveria ser o contrário. Contudo, da mesma forma, como apontado por Raupp e Pinho (2015a), os resultados podem indicar que se essas prefeituras atenderam ao solicitado, então não parece impossível atender à Lei, o que leva a questionar as razões das outras prefeituras não atenderem ou atenderem parcial e pobremente à Lei.

\subsection{Resumo da realidade da transparência passiva}

Apresentados os resultados individuais de cada categoria, nesta seção pretende-se realizar um balanço da transparência passiva dos maiores municípios brasileiros. A síntese em dados quantitativos consta na Tabela 1.

\section{Tabela 1: Síntese da transparência passiva dos maiores municípios brasileiros}

\begin{tabular}{l|c|c}
\hline \multicolumn{1}{c|}{ Categorias } & N. & Percentual \\
\hline Prefeituras em que não foi possível encaminhar a solicitação de informação. & 11 & $3,89 \%$ \\
\hline $\begin{array}{l}\text { Prefeituras cuja solicitação foi encaminhada, mas não houve retorno, ou o retorno } \\
\text { foi insuficiente, ou o retorno ocorreu após o prazo legal. }\end{array}$ & 209 & $73,85 \%$ \\
\hline Prefeituras em que a solicitação foi encaminhada e houve retorno satisfatório. & 63 & $22,26 \%$ \\
\hline Total & 283 & $100,00 \%$ \\
\hline
\end{tabular}

Fonte: Dados da pesquisa (2015) 
De maneira geral, o que se percebe a partir da Tabela 1 é que 220 (duzentas e vinte) $(77,74 \%)$ prefeituras foram consideradas intransparentes na forma passiva, segregadas assim: em 11 (onze) (3,89\%) prefeituras os portais não permitiram o envio da solicitação, enquanto para 209 (duzentas e nove) $(73,85 \%)$ prefeituras até foi possível o envio da solicitação, porém, não houve retorno satisfatório. Já 63 (sessenta e três) $(22,26 \%)$ prefeituras foram consideradas transparentes, pois o envio da solicitação ocorreu e o retorno foi considerado satisfatório. A escolha por municípios maiores pressupunha resultados mais animadores, já que estava circunscrita a um universo onde o desenvolvimento e a modernidade se fazem mais presentes, o que se pressupunha também incluir uma sociedade civil mais ativa e executivos mais sintonizados com as imposições da lei.(RAUPP; ANDRADE; PINHO, 2015) As razões utilizadas para se trabalhar com municípios maiores (STYLES; TENNYSON, 2007; RAUPP; PINHO, 2011; CRUZ et al., 2012; RAUPP, 2014) não foram confirmadas no empírico.

Recomenda-se às prefeituras da primeira categoria que revejam o aparato tecnológico mantido com o objetivo de atender às exigências da LAI, no sentido de tornar possível o envio da solicitação de informação. Além disso, entende-se que estas prefeituras, bem como prefeituras das outras categorias, podem disponibilizar plataformas digitais específicas para o envio da solicitação de informação para que não transfiram esta atribuição, conforme Michener, Moncau e Velasco (2014), para o site de suas ouvidorias ou para o canal "Fale Conosco". Ainda segundo os autores, para que uma lei de acesso à informação funcione e seja usada é importante que o processo para o envio de pedidos e o recebimento de respostas seja o mais simples possível. É fundamental, portanto, que todo governo adote plataformas digitais que tornem esse processo descomplicado e eficiente. $\mathrm{O}$ ideal seria que uma plataforma também fornecesse uma ferramenta de busca para o cidadão identificar respostas a pedidos similares, evitando a custosa repetição de esforços em relação a pedidos e respostas análogos. Para a segunda categoria, considerando o alto contingente de prefeituras que não deram retorno, fica a dúvida se realmente receberam o pedido. Neste caso, recomenda-se que a própria plataforma de recebimento das solicitações possa encaminhar uma mensagem confirmando o recebimento, característica identificada em poucas plataformas. Ainda nesta categoria foram identificados retornos insuficientes (dentro e fora do prazo). Nestes casos, a transparência passiva pode ser vista como aquela encontrada em uma sociedade mais desenvolvida, mais participativa, o que não é o caso da sociedade brasileira. Os entes estatais conformam-se em atender, quando muito, às exigências da lei em geral, no caso a LAI (RAUPP; PINHO, 2015a).

Para Raupp e Pinho (2015a), um contexto como este suscita a necessidade de separar a tecnologia do exercício da transparência, pois, em alguns casos nem a tecnologia necessária está presente; já em outros - a maioria - as respostas não são dadas ou quando chegam são insuficientes para responder à questão formulada e encaminhada às câmaras. Ainda segundo os autores, parece haver um aparato tecnológico (quando há) e um aparato político, programado para atender às demandas da sociedade civil no sentido do aumento da transparência. Em poucos casos, como visto, esses aparatos estão alinhados, estabelecem um diálogo e aproximação. Se não há transparência, consequentemente estas prefeituras não contribuem, em uma perspectiva mais ampla, com avanços democráticos, conforme propunham Zuccolotto, Teixeira e Riccio (2015). 


\section{Conclusões}

$\mathrm{O}$ artigo apresentou os resultados do estudo que teve por objetivo investigar a realidade da transparência passiva de prefeituras dos maiores municípios brasileiros. Foram considerados maiores municípios aqueles com população superior a 100.000 (cem mil) habitantes, totalizando 283 (duzentos e oitenta e três) municípios. Como resultados gerais, 220 (duzentas e vinte) $(77,74 \%)$ prefeituras foram classificadas como intransparentes na forma passiva, em razão de os portais não permitirem o envio da solicitação, ou, mesmo diante da possibilidade de envio da solicitação, o retorno não ter sido satisfatório. Por outro lado, 63 (sessenta e três) $(22,26 \%)$ prefeituras foram consideradas transparentes, pois o envio da solicitação ocorreu e o retorno foi satisfatório. O descumprimento da lei ocorreu na maioria dos municípios, de formas diferentes, seja por problemas no portal, seja em razão de problemas no retorno às solicitações em que o envio foi possível. Desvendou-se uma realidade de transparência passiva que parece não coadunar com o porte do Poder Executivo dos maiores municípios brasileiros.

Os resultados obtidos contribuem de forma prática e teórica. Em termos práticos, tem-se um diagnóstico da transparência passiva de um conjunto considerável de municípios brasileiros. Considerável também é o porte populacional de tais municípios. Sendo o número e o porte dos municípios relevantes, os achados contribuem para um diagnóstico situacional da realidade da transparência passiva. Soma-se às duas características (número e porte dos municípios), o fato de que foi possível investigar municípios de todos os estados brasileiros, formando um mosaico praticamente de todo o país. Por tratar-se de uma obrigação legal, os resultados podem ser utilizados pelos municípios enquadrados na primeira e segunda categorias para se ajustarem às exigências legais. Já os órgãos fiscalizadores ou mesmo os cidadãos podem, a partir dos resultados, inferir sobre os municípios que desrespeitam as exigências de transparência passiva. Do ponto de vista teórico, é evidente a carência de estudos sobre transparência, particularmente em relação à transparência passiva, tema discutido de forma incipiente em eventos e periódicos nacionais.

A opção por encaminhar apenas uma solicitação, sendo que ela tratava de um assunto específico, em que muitos municípios, mesmo de porte maior, acabam não realizando essa atividade (viagem do prefeito ao exterior), pode ter interferido no resultado. Tal escolha representa uma limitação do estudo, ou seja, em determinados casos é possível que a falta de resposta esteja vinculada a não existência desse tipo de fato (viagem do prefeito ao exterior). Cabe ressaltar que os resultados obtidos se limitam aos casos selecionados, sendo as considerações direcionadas para o objeto empírico investigado, sem generalizações, para outras prefeituras ou entes de outras esferas no Brasil. Outra limitação relaciona-se à escassez de estudos relativos ao assunto, principalmente em relação à transparência passiva, dificultando a comparação dos resultados com outros estudos. A terceira limitação diz respeito à velocidade de mudanças das TIC e da própria estrutura dos portais eletrônicos, ou seja, os dados apresentados indicam a realidade do período de coleta. Neste sentido, outros estudos são encorajados a fim de que tais limitações sejam amenizadas.

\section{Referências}

ALLEGRETTI, Daiane D. S.; PLATT NETO, Orion A. Funcionalidades, limitações e potencialidades do Portal da Transparência do Estado do Rio Grande do Sul. Revista Catarinense da Ciência Contábil, v. 9, n. 26, p. 79-95, 2010. 
ANGÉLICO, Fabiano. Lei de acesso à informação pública e seus possíveis desdobramentos para a accountability democrática no Brasil. Dissertação (mestrado) - Escola de Administração de Empresas de São Paulo, Fundação Getúlio Vargas, São Paulo, 2012.

ANGÉLICO, Fabiano; TEIXEIRA, Marco A. C. Acesso à informação e ação comunicativa: novo trunfo para a gestão social. Desenvolvimento em Questão, v. 10, n. 21, p. 7-27, 2012.

ARTIGO 19. Balanço de 1 ano da Lei de Acesso à Informação Pública. São Paulo, 2013.

BAIRRAL, Maria A. C.; SILVA, Adolfo H. C.; ALVES, Francisco J. D. S. Transparência no setor público: uma análise dos relatórios de gestão anuais de entidades públicas federais no ano de 2010. Revista de Administração Pública, v. 49, n. 3, p. 643-675, 2015.

BRANS, Marleen; PETERS, B. Guy; VERBELEN, Bart. Rewards at the top: cross-country comparisons across offices and over time. In: BRANS, Marleen; PETERS, B. Guy. Rewards of high public office in Europe and North America. New York: Routledge, 2012.

BRASIL. Lei de Responsabilidade Fiscal. Lei Complementar $n^{\circ} 101$, de 04 de maio de 2000. Presidência da República. Casa Civil. Subchefia para assuntos jurídicos. Brasília, 2000.

BRASIL. Lei da Transparência. Lei Complementar $n^{\circ} 131$, de 27 de maio de 2009. Presidência da República. Casa Civil. Subchefia para assuntos jurídicos. Brasília, 2009.

BRASIL. Lei de Acesso a Informações Públicas. Lei $n^{\circ} 12.527$, de 18 de novembro de 2011. Presidência da República. Casa Civil. Subchefia para assuntos jurídicos. Brasília, 2011.

CASADO, Lucía. El acceso a la información ambiental en España: luces y sombras. Derecho PUCP, n. 70, p. 241-278, 2013.

CRUZ, Cláudia F. et al. Transparência da gestão pública municipal: um estudo a partir dos portais eletrônicos dos maiores municípios brasileiros. Revista de Administração Pública, v. 46, n. 1, p. 153-176, 2012.

CUNHA, Maria A. V. C. da. Portal de serviços públicos e de informação ao cidadão: estudo de casos no Brasil. Tese (doutorado) - Programa de Pós-Graduação em Administração, Faculdade de Economia, Administração e Contabilidade da Universidade de São Paulo, São Paulo, 2000.

CURTIN, Deirdre; MEIJER, Albert Jacob. Does transparency strengthen legitimacy? Information Polity, v. 11, p. 109-122, 2006.

ETZIONI, Amitai. Is transparency the best disinfectant? The Journal of Political Philosophy, v. 18, n. 3, p. 389-404, 2010.

FILGUEIRAS, Fernando. Além da transparência: accountability e política da publicidade. Lua Nova, v. 84, p. 65-94, 2011.

FOX, J. Government transparency and policymaking. Public Choice, v. 131, n. 1, p. 23- 44, 2007.

FRANCO, Luciane M. G. et al. Nível de divulgação eletrônica da contabilidade pública dos municípios do Paraná no ambiente da Internet. Revista de Ciências da Administração, v. 16, n. 38, p. 140-153, 2014.

INSTITUTO BRASILEIRO DE GEOGRAFIA E ESTATÍSTICA. Sinopse do Censo Demográfico 2010. Rio de Janeiro, 2011.

JARDIM, José M. A Lei de Acesso à Informação Pública: dimensões político-informacionais. In: ENCONTRO NACIONAL DE PESQUISA EM CIÊNCIA DA INFORMAÇÃO, 13., 2012, Rio de Janeiro. Anais... Rio de Janeiro, 2012.

LICHT, Jenny Fine. Policy area as a potential moderator of transparency effects: an experiment. 
Public Administration Review, v. 74, p. 361-371, 2014.

LOPES, Cristiano A. Acesso à informação pública para a melhoria da qualidade dos gastos públicos literatura, evidências empíricas e o caso brasileiro. Caderno de Finanças Públicas, v. 8, p. 5-40, 2007.

LOPES, Karen M. G.; ASSUMPÇÃO, Rita C. Processos e solução tecnológica para implementação da lei de acesso à informação (LAI). In: CONGRESSO CONSAD DE GESTÃO PÚBLICA, 2013, Brasília. Anais... Brasília, 2013.

LOUREIRO, Maria R.; TEIXEIRA, Marco A. C.; PRADO, Otávio. Construção de instituições democráticas no Brasil contemporâneo: transparência das contas públicas. Organizações \& Sociedade, v. 15. n. 47, p. 107-119, 2008.

MACADAR, Marie A.; FREITAS, Jorge L.; MOREIRA, Cristiano R. Transparência como elemento fundamental em governo eletrônico: uma abordagem institucional. Revista Gestão \& Tecnologia, v. 15, n. 3, 2015.

MICHENER, Gregory. Conceptualizing the quality of transparency. In: $1^{\text {st }}$ GLOBAL CONFERENCE ON TRANSPARENCY. Annals...Newark, 2011.

MICHENER, Gregory; BERSCH, Katherine. Identifying transparency. Information Polity, v. 18, p. 233-242, 2013.

MICHENER, Gregory; MONCAU, Luiz F. M.; VELASCO, Rafael. Estado brasileiro e transparência: avaliando a aplicação da Lei de Acesso à Informação. Rio de Janeiro: FGV e Open Society Foundations, 2014.

NIWA, Tiago H.; LIMA, Isaura A. de. O desenvolvimento e os atuais desafios para a consolidação da transparência na Administração Pública. In: SEMINÁRIO NACIONAL DE PLANEJAMENTO E DESENVOLVIMENTO, Curitiba. Anais... Curitiba, 2013.

OLIVEIRA, João B. F. de. Governo eletrônico: uma análise quantitativa do uso de sistemas de informação em prefeituras. In: ENCONTRO DA ANPAD, 30., 2006, Salvador. Anais... Rio de Janeiro, 2006.

PAES, Eneida B. A construção da lei de acesso à informação pública no Brasil: desafios na implementação de seus princípios. Revista do Serviço Público, v. 62, n. 4, p. 407-423, 2011.

PELICIOLI, Angela C. A lei de responsabilidade na gestão fiscal. Revista de Informação Legislativa, v. 37, n. 146, p. 109-117, 2000.

PINHO, José A. G. de. Investigando portais de governo eletrônico de estados no Brasil: muita tecnologia, pouca democracia. Revista de Administração Pública, v. 42, n. 3, p. 471-493, 2008.

PINHO, José A. G. de; SACRAMENTO, Ana R. Accountability: já podemos traduzi-la para o português? Revista de Administração Pública, v. 43, n. 6, p. 1343-1368, 2009.

PRADO, Otávio; LOUREIRO, Maria R. G. Governo eletrônico e transparência: avaliação da publicização das contas públicas das capitais brasileiras. Revista Alcance, v. 13, n. 3, p. 355-372, 2006.

RAUPP, Fabiano M. Construindo a accountability em câmaras municipais do estado de Santa Catarina: uma investigação nos portais eletrônicos. Tese (doutorado) - Curso de Administração, Universidade Federal da Bahia, Salvador, 2011.

RAUPP, Fabiano M. Prestação de contas de executivos municipais de Santa Catarina: uma investigação nos portais eletrônicos. Administração Pública e Gestão Social, v. 6, n. 3, p. 151-158, 2014. 
RAUPP, Fabiano M.; ABREU, Eliza; ABREU, Mayara B. Disponibilização de informações à sociedade em meios eletrônicos: um estudo nas prefeituras dos maiores municípios brasileiros. Revista Catarinense da Ciência Contábil, v. 14, n. 42, p. 41-54, 2015.

RAUPP, Fabiano M.; PINHO, José A. G. Prestação de contas por meio de portais eletrônicos de câmaras municipais: um estudo de caso em Santa Catarina antes e após a Lei da Transparência. Revista de Contabilidade do Mestrado em Ciências Contábeis da UERJ, v. 16, n. 3, p. 81-98, 2011.

RAUPP, Fabiano M.; PINHO, José A. G. Accountability em câmaras municipais: uma investigação em portais eletrônicos. Revista de Administração, v. 48, n. 4, p. 770-782, 2013.

RAUPP, Fabiano M.; PINHO, José A. G. A lei, ora a lei: um balanço da (in)transparência passiva em câmaras municipais brasileiras. In: ENCONTRO DE ADMINISTRAÇÃO DA INFORMAÇÃO, 5., 2015, Brasília. Anais... Rio de Janeiro, 2015a.

RAUPP, Fabiano M.; PINHO, José A. G. Prestação de contas no legislativo local antes e depois da Lei de Acesso à Informação. ConTexto, v. 15, n. 29, p. 30-46, 2015 b.

RAUPP, Fabiano M.; ANDRADE, Rodrigo G. de; PINHO, José A. G. de. Em busca da transparência ativa em câmaras: uma investigação nos maiores municípios brasileiros. In: SEMINÁRIOS EM ADMINISTRAÇÃO - FEA - USP, 28., 2015, São Paulo. Anais... São Paulo, 2015.

SACRAMENTO, A. R. S.; PINHO, José A. G de. Transparência na administração pública: o que mudou depois da lei de responsabilidade fiscal? Um estudo exploratório em seis municípios da região metropolitana de Salvador. Revista de Contabilidade da UFBA, v. 1, n. 1, p. 48-61, 2007.

SANTANA JUNIOR, Jorge J. B. et al. Transparência fiscal eletrônica: uma análise dos níveis de transparência apresentados nos sites dos Poderes e Órgãos dos estados e do Distrito Federal do Brasil. Revista de Educação e Pesquisa em Contabilidade, v. 3, n. 3, p. 62-84, 2009.

SILVA, Lino M. Contabilidade governamental: um enfoque administrativo. São Paulo: Atlas, 2008.

SILVA, Wendel A. C.; PEREIRA, Maria G.; ARAÚJO, Elisson A. T. Estudo da criação de valor econômico e transparência na administração pública. Desenvolvimento em Questão, v. 12, n. 26, p. 142-176, 2014.

SILVEIRA, Marco A. K. Lei de acesso a informações públicas (Lei $\mathrm{n}^{\circ}$ 12.527/2011): democracia, república e transparência no Estado Constitucional. Revista da Procuradoria Geral do Estado, v. 33 , n. 69, p. 231-260, 2012.

STYLES, Alan K.; TENNYSON, Mach. The accessibility of financial reporting of U.S. municipalities on the Internet. Journal of Public Budgeting, Accounting \& Financial Management, v. 19, n. 1, p. $56-92,2007$.

SUK KIM, Pan et al. Toward participatory and transparent governance: report on the sixth global forum on reinventing government. Public Administration Review, v. 65, n. 6, p. 646-654, 2005.

WARMLING, Natalia N.; BERNARDES, Marciele B.; SANTOS, Paloma M. A lei de acesso à informação e o dever de transparência: uma análise do exercício da transparência passiva no âmbito dos Tribunais de Justiça brasileiros. In: ROVER, Aires J.; SANTOS, Paloma M.; MEZZAROBA, Orides. (Org.). Governo eletrônico e inclusão digital: textos produzidos para o 19 encontro íberolatino-americano de governo eletrônico e inclusão digital no ano de 2014 em Florianópolis. Florianópolis: Conceito Editorial, 2014.

ZUCCOLOTTO, Robson; TEIXEIRA, Marco A. C.; RICCIO, Edson L. Transparência: reposicionando o debate. Revista Contemporânea de Contabilidade, v. 12, n. 25, p. 137-158, 2015. 